\title{
The Power of Song in the Struggle for Health and Development Outcomes in Africa: Lessons for Social and Behaviour Change Programmes
}

Fayoyin $\mathbf{A}^{1 *}$ and Nieuwoudt $\mathrm{S}^{2}$

${ }^{1}$ Regional Communication Adviser, United Nations Population Fund (UNFPA), Johannesburg, South Africa

${ }^{2}$ School of Public Health, University of the Witwatersrand, Johannesburg, South Africa

\begin{abstract}
This paper explores the use of music in the struggle for health and development outcomes in Africa. From our case studies, we found that development agencies and other stakeholders employ songs for social mobilisation, information diffusion, partnerships with high profile global, regional and national artists and fundraising for humanitarian response. The lyrics from the songs range from the entertaining to the satirical and from defiance of oppression to hope for the future. The study shows that charity songs are also used to frame and reframe Africa's development issues by different artists. Finally, we conclude that music is strong in disseminating information in social development but ineffective in influencing collective behaviour on structural inequalities and the root causes of underdevelopment. In view of the ambiguous impact of music in behaviour and social change, we recommend an interdisciplinary framework for a global theory of songs in development. The use and misuse of charity songs also deserves further investigation.
\end{abstract}

Keywords: Charity songs; Health messages; Popular movements; Music advocacy; Social change

\section{Introduction}

The African continent is home to a multitude of health and development challenges which are well established in the literature on international development. Modavo lists some of the struggles that confront African countries as chronic poverty, high level of disease burden, gender inequities and humanitarian crisis [1]. Life expectancy is shorter in Africa than anywhere in the world, while almost half of the population of sub-Saharan Africa lives on less than the international poverty line of $\$ 1.25$ per day [2]. Although the continent is undergoing significant economic growth, there are marked inequalities that contribute to ill-being for the vast majority. The continent also experiences periodic humanitarian crisis such as famine, floods, and disease outbreaks. Thus the 2014 Millennium Development Goals report for Africa concludes that the continent requires a comprehensive and multidimensional transformation to enhance the wellbeing of the population [3].

To achieve this objective, several interventions, including social and behaviour change interventions through songs, have been implemented by different development agencies. Aid agencies and other stakeholders have invested in and continue to support the composition, production and dissemination of songs to promote social and health issues. Individual musicians have also produced songs for targeted behavioural and social changes. In light of this, we explore the power of songs to transform health and development outcomes in Africa. Our focus is not a hermeneutical or harmonic analysis of the temporal or tonal elements, timbre or dynamic values of music. Neither are we concerned with discourse analysis or comparative interpretation of structures, grammar and other textural elements of the songs. Rather, we adopt a reflective perspective on the role of songs in achieving health and development programming objectives based on the messages encapsulated in the songs. Our theoretical premise is to establish the reality of the transformative power and regenerative potential of music for public health and development outcomes, using a number of case studies.

From our case studies, we found that songs have contributed to advocacy, networking with musicians and fundraising for health and development. They have also been used as tools of information dissemination, awareness creation and other intermediate elements along the pathway to behaviour and social change. Besides, music has substantial entertainment and emotional value and is able to spread messages in an indirect way in a variety of settings. However, we are unable to establish the 'magical effect' of songs on behaviour and social change. Evidence on the role of music in influencing structural determinants of underdevelopment and public health problems remains tenuous and ambiguous. On this basis, we call for more empirical investigation and robust theorising on the relationship between songs and development.

\section{Unpacking the role of song in society}

There is considerable debate on the influence of music on social change. Examining why music matters in social life, Turino posits that music is at the heart of social interaction in many societies, as it is used to create and express diverse emotional and social experiences [4]. Turino's argument for music as a basis for creating shared identity out of diversity and as a tool for sharing cultural knowledge is core to those who seek to employ music for change processes. Beyond lyricism, Cook points out, songs have great potential to move 'people profoundly' 'involuntarily', and 'subliminally.' According to the author, "a few pitches durations, timbre, and dynamic values can unlock the most hidden content of man's spiritual and emotional being" [5]. Music's power to move can be individual, but also has a collective nature. Cross and Morley, who investigated music from an evolutionary perspective, conclude that music promotes group cohesion, facilitates emotional bonding, enhances sexual selection

${ }^{*}$ Corresponding author: Fayoyin A, Regional Communication Adviser, United Nations Population Fund (UNFPA), Johannesburg, South Africa, Tel: +27 11603 5303; E-mail: afayoyin@gmail.com

Received April 26, 2017; Accepted June 23, 2017; Published June 30, 2017

Citation: Fayoyin A, Nieuwoudt S (2017) The Power of Song in the Struggle for Health and Development Outcomes in Africa: Lessons for Social and Behaviour Change Programmes. J Mass Communicat Journalism. 7: 342. doi: 10.4172/21657912.1000342

Copyright: @ 2017 Fayoyin A, et al. This is an open-access article distributed under the terms of the Creative Commons Attribution License, which permits unrestricted use, distribution, and reproduction in any medium, provided the original author and source are credited. 
and cultural connectivity and is capable of "engaging and rewarding communities, groups and individuals." [6]. Bastien adds that we discover local narratives of broader phenomena, such as HIV, in music generated from within communities [7]. Such narratives emerge from and reflect lived experiences. However, rather than uncritically observe music as a natural phenomenon, we focus on its purposive use to move particular agendas.

Evidence from political and social contexts has shown that music has been used as a channel to persuade, control or advance social causes. This function falls within what Perris calls 'music as propaganda' [8]. The author argues that when music is used to spread ideas, information or rumour for an institution or cause, this amounts to propaganda. Thus, protests songs, religious music, songs that promote nationalistic ethos, or songs used for social and political commentary are within the ambit of propaganda music. We, however, differ from this blanket configuration of message-oriented music as propaganda. Although there have been negative deployments of music for mind management and whipping up of negative ethnic sensibilities, music has been pivotal for the traditional, social and political development of many societies. Our case studies explore music intentionally created to convey pro-social messages and leverage support for issues of health and development. In doing so, we continue Askew's work of highlighting the growing proclivity of the development actors to commission popular culture to serve socio-political agendas [9], but with an optic of their implied impact rather than of cultural appropriation.

While essentialists and poets portray music as a universal language and part of humanity's code of narration, it has also been instrumentalized, harnessed as a tool of mass communication and collective behaviour. For example, songs have been composed for and against apartheid [10]; used to enhance political movements [4]; fight for social injustice and promote cultural awareness [11], employed for didactic and other educational purposes [12]; deployed as a tool of therapy for specific social conditions and clinical illnesses [6] and used for reconciliation in post-conflict situations, based on the theory of medical ethnomusicology [13]. Moreover, due to music's wide appeal across class, culture, gender and religious beliefs, it has featured as a vital element of social movements, cultural solidarity, and political mobilisation $[8,14]$. Music also is one of the channels employed by entertainment education (herein edutainment), which is a strategy that uses popular media to move people emotionally as well as engage in discussion and debate, with an ultimate aim of transforming society [15].

The seemingly pervasive power of music in society serves as the premise of our investigation on the relationship between songs and development agendas.

\section{Case studies on song and Africa's development issues}

The scope of music-based approaches in development programming in Africa is vast. A survey of interventions of development agencies and activists shows that songs have been used to address girl child education, environment protection and conservation, population dynamics, water and sanitation, malaria prevention, cholera management and HIV prevention. Africa's development challenges have also led to a multitude of charity songs by iconic international and national musicians. In broad terms, music has been a tool of advocacy and awareness raising, seeking to achieve development results [16]. We shall illustrate how songs have been deployed to tackle various development issues from our cluster of three thematic areas: chronic poverty, humanitarian crises and specific health agendas, in this case family planning.

\section{Songs on poverty eradication}

Songs have been leveraged to address some of the continent's most intractable development issues, in particular poverty. In 2000, world leaders at the UN Millennium Summit made a commitment to end poverty by 2015 . Several policy and programmatic interventions have been implemented, with music being an integral part of social (and financial) mobilisation to achieve this objective.

At the global level, there is a rich history of musical collaborations to draw attention to chronic poverty in Africa. In a 1999 joint venture between the United Nations Development Program (UNDP) and Cisco Systems, NetAid coordinated three simultaneous concerts in London, New Jersey and Geneva featuring popular artists to raise funds and awareness for the Jubilee 2000 debt forgiveness movement. While these concerts jointly raised over $\$ 800,000$ from 80 countries, the impact of the single "New Day" that featured U2 lead singer Bono, is more ambiguous. Increasingly sophisticated efforts to bring together musical celebrities and music to end poverty, coinciding with G8 summits, were pursued again through the Live 8 concerts in 2005 with the tagline "Make Poverty History" and again in 2008, through an initiative under the auspices of Bono's One Campaign. In the latter case, over 100 international artists, including Sting, Mumford and Sons and Jay $\mathrm{Z}$ produced their popular protest songs of various digital media and performed on global stages to this end [17]. Beyond fundraising, these latter efforts were based on the notion that music has the power to effectively unite groups around a particular social issue and to put pressure on the G8 leaders to address global poverty.

As a tool for advocacy and awareness raising the types of messages conveyed through these songs are noteworthy. An excerpt from HipHop song Immortal Technique - the Philosophy of Poverty follows:

You see, third world countries are the rich places, abundant in resources, and many of these countries have the capacity to feed their starving people and the children we always see digging for food in trash on commercials. But plutocracies in other words a government run by the rich, such as this one (sic US) and traditionally oppressive European states, force the third world into buying overpriced, unnecessary goods, while exporting huge portions or their natural resources [18].

As illustrated above, lyrics from songs which address poverty tend to be serious and depict profound inequalities that exist among the rich and poor countries. In addition, some of them portray the activities of transnational organisations and their government collaborators that are considered as the causes of global poverty, following a discourse of globalisation. The people singing these lyrics were predominantly from G8 countries. One critique of these initiatives (NetAid and Live 8 particularly) was that there were few African's represented among the artists. However, the question remains: Did these political protest songs elicit the needed action to change the dynamics they described?

To be clear, music collaborations are not the sole domain of the so-called developed world, with examples of African efforts to address poverty tracking in parallel to those of Western origin. In 2004, 18 top musicians from Africa, in partnership with the UNDP produced a song entitled "We are the Drums" which was a call to Africa to take responsibility for their development. The lyrics encouraged African to stop "being victims of war, victims of poverty, victims of hunger." The song also invoked the folk culture of the continent and requested Africans to "act as a tam-tam drum" to spread the message, making poverty history in Africa. As a complement to "We are the Drums," an 11 track musical album sung in 18 African languages was produced by 37 top musicians across the region. The music was launched in many 
African countries as part of the commemoration of the International Day for Poverty Eradication. The album and its video version have been aired on radio and TV stations in many African countries.

Another African-based music venture was initiated in 2008 entitled "8 Goals for Africa" to support the achievement of the MDGs and maximise the power of music during the World Cup of 2010 [19]. This involved 8 African artists who recorded a song for each of the MDGs. The artists were also involved in global and regional antipoverty campaigns such as Global Stand Up Against Poverty, Africa Stand Up Against Poverty and Free the Hungry Billion programme. The project integrated performances by the artists at special events to draw attention to the promise to end poverty on the continent.

Beyond commissioned songs, popular musicians have highlighted the issue of poverty in various parts of Africa. Both Fela Anikulapo Kuti and his son, Femi Kuti have produced several songs which address poverty in Africa with references to poverty in many parts of the world. For example, Fela sang about "suffering and smiling" while Femi sang "Anymore" depicting the impact of poverty. Below is an excerpt from Anymore.

When you see what is going on in the world today,

You will agree that poverty is winning the game,

More people are suffering,

More people are very poor,

The suffering people can't take anymore, anymore, anymore, anymore.

African folk songs address different elements in the struggle for development. Such lyrics tend to confront the facets and manifestations of poverty, including its perceived root causes of laziness (as compared with critiquing globalisation). Many African traditional songs promote diligence, which is seen as an antidote to poverty. Soetan found that African maxims, folksongs and proverbs encourage individuality, industry and thrift, which are essential to wealth creation among the Yoruba's from Western Nigeria [20]. Ajisafe [21] captures one of the folksongs as follows:

When day breaks,

Every tradesman betakes to his calling,

The spinner takes up the spindle,

The weaver bends over the shuddle,

The farmer takes up his implements

The hunter picks up his weapons,

The fisherman wends his way to the waterside.

In general, songs that address poverty tend to be serious and deal with social, cultural and political dimensions of poverty issues in Africa. They also serve as social commentaries of government policies or agenda of multilateral corporations or encouragement for individuals to abhor preconditions for being poor, although in our examples there are some distinctions that can be made. Most of the video songs on poverty are accompanied by powerful and emotional images of suffering from disease and malnutrition intended to evoke emotion by the audience. Often, calls to action tend to be individualised, such as working harder or spreading the word.

\section{Songs during humanitarian crisis}

In contrast with chronic development issues, like poverty, we reviewed the role of music in times of crisis, such as famine and disease outbreak. Between 1983 and 1985, two African countries Ethiopia and Eritrea experienced a major famine from which over 2 million people perished. The grim disaster led to a massive humanitarian response, including unprecedented engagement with various stakeholders. The crisis resulted in substantial international and regional response, including the use of charity songs by popular musicians. One of the songs for global awareness, mass mobilisation and fundraising was "Do they Know It's Christmas" by Band Aid, a group of British and Irish pop stars and artists. The group was established in 1984 to raise funds for the crisis and at least 40 music stars, selected on the basis of their popularity, participated in the recording. The song was a commercial success and raised over $\$ 24$ million. However, it has been criticised on various grounds, especially for its lyrics. Some of the offensive lyrics include generalisations that nothing grows in Africa $(\mathrm{Oh}$, where nothing ever grows, no rain or rivers flow), reference to divine power in the changing of Africa (But say a prayer to pray for the other ones, At Christmastime) and the savior mentality of Western countries as reflected in the following excerpts:

And the Christmas bells that ring there,

Are the clanging chimes of doom,

Well tonight thank God it's them instead of you,

And there won't be snow in Africa this Christmastime.

A similar critique was made of another emblematic charity song of the era, "We are the World," which was produced by a group of artists called USA for Africa in 1985. Although the song became an anthem for the humanitarian response because of its memorable melody, emotional build up, repetitive chorus and the popularity of the artists involved, lyrics like "we are saving our own lives" reek of selfrighteousness and self-glorification. Whether the commercial success of such songs and the funds raised were worth the over-simplification of development issues and 'othering' of Africa remain a point of debate in development circles.

More recently, an Ebola outbreak in West Africa has attracted the interest of musicians, both international and African. Ebola is a rare tropical disease which spreads through direct contact with infected fluid virus such as blood, sweat and vomit, which by late July 2015 had killed over 11,200 people in at least five countries. Early on the outbreak was fuelled by myths and misconception on its reality and spread, distrust in the health system, and lack of awareness on how to contract it, which led to the creative use of songs for information diffusion and fundraising by various development agencies and musicians [22,23]. Among them, in December 2014, were none other than Band Aid. They released a new version of their 1984 charity song "Do they Know it's Christmas" to raise funds for Ebola victims in West Africa. While this version changed some of the previous contentious lyrics, analysts still argued that the song "left a bad taste in the mouth" because of its "weird and inappropriate lyrics and patronizing spectacle of so many white Western artists singing to an amorphous and anonymous group of Africans." [24]. Others commentators describe the music as clumsy and patronizing [25].

More local attempts and using song to respond to the outbreak were also mixed. In Liberia three artists came up with a song "Ebola in Town" which had a corresponding dance tune to enhance its stickiness. 
Nevertheless, the lyric were more like "commandments, admonition and warning" about the spread and danger of Ebola. The entire song was more of an infomercial and contained some inaccurate information. It adopted a fear appeal and had a relatively scary undertone. Some of the lyrics include:

Ebola in town o; Ebola is wicked; It can kill you quick; Don't touch your friend; Ebola is more than HIV/AIDS' No kissing; No eating something, Ma pa Jehovah, Please save us from Ebola....

Another song, "Africa Stop Ebola”, produced by top French African musicians also contained information on how Ebola is spread and how people can protect themselves and invariably their communities with a markedly different tone. The song contains several calls to solidarity such as: "Mama Africa get up, and stand united as we use to do before for other battles. Ebola you also shall be defeated" packaged in as mixture of reggae, afro beat, rap, solo and sentimental melodies peculiar to West Africa. The goal was also to leverage the power of music and the image of popular musicians in the fight against the epidemic.

A key lesson from songs responding to humanitarian crises is the importance of framing as opposed to a focus on genre or particular artists. Some lyrics are intended to inform while others are intended to evoke emotion from international audiences for donation, with both political undertones and overtones. Examining the use of songs during the Ebola epidemic, Tuker identifies three types of popular music sensitization, information and political tunes [26]. The songs were used for individual and collective expression, escapism, information and political contestation. But we also note that some of the songs popularised misconceptions and misinformation about the disease, which underscores the potential negative impact of songs in health communication. In terms of the broader framings of development, charity songs by Western artists fuelled controversies on the ethnocentric narratives and 'messiah complex' of Western countries about developing countries.

\section{Songs to promote family planning}

Development agencies also have identified the power of songs in mobilizing different audience groups for more targeted public health outcomes. Specifically, within the ambit of maternal and child health, songs with messages about family planning in Africa have been commissioned by various aid agencies. One of the innovative projects based on an edutainment approach was initiated by the Johns Hopkins University (JHU). From 1990-1992, two prominent musicians (King Sunny Ade and Onyeka Onwenu) were invited to produce two theme songs for family planning interventions: "Wait for Me" and "Choices". The songs integrated critical issues on family planning such as use of contraceptive devices and awareness on the impact of unwanted pregnancies. "Choices" encouraged couples to make choices on the number of children they want and not have children by chance. Its lyrics include:

\section{Choices, Choices, Choices}

We can make choices,

This is the time,

When we have to make choices,

Take a stand,

On the kind of world we want,

Or the children we are not prepared for.

We can make choices.
Furthermore, other prominent musicians from a different genre (Fuji musicians, Kollingon Ayinla and Ayinde Barrister) developed tunes to promote family planning [27]. An evaluation of the music project points to significant changes in people's contraceptive attitudes and behaviour attributed to media promotion of family planning. For the JHU family planning songs, it was found that an average of 64 percent of respondents confirmed that they had seen and heard the music while 95 percent of this group correctly identified the message in the music. The study also confirmed that modern contraceptive use among the target audience increased. Within our review, this was one of the most compelling pieces of evidence that songs may directly influence behaviour change. However, we would like to underscore the challenge with direct attribution of specific behaviour change to the music intervention, as the songs formed part of broader family planning efforts during the period.

Songs have also been used to promote Family Planning (FP) and child health in the Democratic Republic of the Congo (DRC). In 2013, ten top artists produced a rumba song on the need to plan families, mobilise the public to support child health and call on government for appropriate actions. A video clip of the song has also been produced for utilisation on national TVs and radios to sensitize the Congolese population on FP. Aid agencies used the song as part of the advocacy messaging to influence government allocation to contraceptives services in the country. The song, complemented with other advocacy activities, contributed to the allocation, for the first time, by the national Government of a budget line for contraceptives in the national budget [28].

Of the three case studies we have considered (poverty, humanitarian crisis and family planning), the more targeted focus on specific behaviours and action provide the most evidence for songs influencing behaviours, both at individual and systems levels. However, in the family planning examples, the songs formed part of a broader mobilisation campaign and attribution claims remain tenuous.

\section{Major issues and implications for social and behaviour change}

From the array of uses of music-based interventions examined above, several critical issues can be identified in the use of songs for health and development. We shall focus on five cross cutting issues in this section.

\section{Songs as a tool of public discussion}

Music has become a major tool of public discussion of health and development issues and the range of music genres (high life, solo, rap, gospel, choir, afro beat, rock and many others) have been used to promote social messages. Sen agrees that public discussion is one of the elements of development which facilitates social conversation and public discussion of health and development issues [14]. Evidence shows that songs have potential for increased public discussions of the issues sung about. For example, songs about Ebola in West Africa have been recognised as simulating public awareness on the epidemic while music on family planning has been instrumental for better understanding of child spacing in Nigeria. But the direct impact of songs on the quality of public discussion still needs more investigation. The diversity of settings in which songs can be used to reach various populations with development information is wide, but it creates major implications for monitoring and evaluation.

\section{Ambiguous effect of songs}

Most development songs are expected to elicit corresponding 
actions, whether at the behavioural or social level. Our analysis shows that songs disseminate health messages through various forms genres such as social commentary, entertainment, mobilisation, and calls for solidarity. Many of them intercede for attitude or behaviour change by individuals or the communities, while others call on the moral conscience of the national or international community for specific actions, such as fundraising. Songs have been useful in relaying health messages, disseminating innovative ideas, popularising social concerns, commenting on specific social practices and even as a form of social therapy for those affected by HIV. The potential of using music to address issues in the pathway to change is not in doubt [29]. However, the specific result being achieved is another significant question to ponder. For example, while endorsing the role of musicians in health communication, Amu raises similar questions on the relationship between songs and development as follows: "What do they say? How does the society receive the message? In other words are they really making any meaningful impact in our lives? What kinds of audience do they target? How often and in what context are such songs performed?" [30]. Ostensibly the questions point to the ambiguous effect of songs in development. Answers to these questions would help in fully understanding the impact of music in public health and development outcomes.

\section{Engagement of music icons for advocacy}

The use of music in health and development is a major tactic of engaging celebrities in advocating for social change. This is based on the premise that involving popular and respected entertainers is an effective means of getting people to adopt a new behaviour. However it is also possible for the messenger to get in the way of the message. For example, the use of Sunny Ade in Nigeria who was known to be a polygamist singing about family planning raised significant dust on his appropriateness as a credible messenger. The agencies involved had to spin the message saying he had learnt his lessons on the dangers of polygamy and was speaking as a convert to the new behaviour. Thus, while celebs are great in attracting attention to social issues, their effectiveness as major change agents is sometimes in question.

\section{Impact of digital and social media on development songs}

The pervasiveness of digital media, characterised by the utilisation of various communication formats such images, video, text, audio and driven by the combination of communication and information technology through the internet has affected the production and dissemination of health related songs. The ubiquity of new media platforms has further increased independent production and sharing of songs on development. Young people are currently using songs of various genres to highlight health and development issues in various parts of the continent. The packaging of songs is now including more creative sound and visual effects. It is therefore argued that the digital media will be critical for greater dissemination of development related messages through songs.

\section{Contentious narratives from Western charity songs}

Africa's development challenges have elicited the production of charity songs by influential artists primarily intended for fundraising. While most of the interventions have been successful in that regard, they have raised several contentious narratives. First, charity songs from Western artists reinforce the "saviour mentality" of developed countries, what is eloquently captured in "The Whiteman Burden: Why the West efforts to aid the rest have done so much ill and little good" [31]. Although Easterly's proposition is on the overall aid structure, the arguments are germane to the use of charity songs. Most of the Western charity songs reflect considerable generalisations on Africa and have been criticised for their patronising signification of Africa. Perhaps in response to this phenomenon, a group called Africa for Norway produced a parody song called Radi-Aid in 2014, which is a direct replica of "We are the World" [32]. It involves popular African artists coming together to mobilise radiators for those affected by extreme winters in Norway to "Save Norwegians from frostbite." The video has nearly 3 million views of YouTube and the group's website engages in robust debates of development through social media channels. The title of the charity song by African artists "We are the drums" also seems to be in direct response to the US for Africa song "We are the World". From these examples, charity songs in general have become a platform for framing and counter framing of Africa's image and thus require more investigations.

\section{Rethinking the influence song in development}

From the foregoing, we have established that songs are part of the package of social and behaviour change interventions to achieve development outcomes. However, questions have been raised on their effectiveness in the struggle for health and development. Specifically on the use of song for HIV in Africa, [29] raised the following question: "What does it mean to 'dance' a syndrome, 'sing' a medical condition and 'act out' an etiology"? In the same vein, we ask: How can we 'tune up' policies through music pitch, timbre and dynamic values or 'drum up' positive behaviour change from policy makers or influential religious leaders, 'chant out' appropriate attitude to condom use by youth, or 'dance out' collective behaviour to eliminate gender-based violence in communities where the practice is prevalent?

These are only a few of the questions that point to the need for a rethinking of the relationship between songs and development. More insightful analysis of the role of music interventions in development programming is critical in better understanding its strengths and limits in behaviour and social change. Such investigations should also explore the use and misuse of charity songs in health and development. Besides, there is emerging evidence that songs have unintended stigmatising effect on singers of some types of music while in many African societies, some folk songs reinforce gender stereotypes and patriarchal structures. Exploring these issues provide additional perspectives on how music impacts development. Further empirical inquiry to build a global theory of songs in development from an interdisciplinary approach involving experts in development studies, health promotion, musicology and ethnomusicology, among others, will enhance the intellectual underpinning of the iconic and indexical power of music in health and development. Finally, health and development issues have transnational ramifications and songs to address them are produced and consumed across cultural boundaries. A global theory of music and development exploring some of the variable discussions in the study is strongly recommended.

\section{Conclusion}

Music is a pervasive feature of contemporary society with transformative and regenerative possibilities. In this study we have attempted to explore the inherent power of songs in health and development struggles. We established that songs have been used to address several development and health related issues such as chronic poverty, famine, disease outbreaks and family planning. However, the anticipated magical effect of songs in social life has not been validated within the development context. We do not suggest that songs are completely ineffective in social and behaviour change. Their role in 
Citation: Fayoyin A, Nieuwoudt S (2017) The Power of Song in the Struggle for Health and Development Outcomes in Africa: Lessons for Social and Behaviour Change Programmes. J Mass Communicat Journalism. 7: 342. doi: 10.4172/2165-7912.1000342

information diffusion, awareness raising and even partnership for resource mobilisation is validated with our case studies. However, their influence in health and development is rather ambiguous and raises questions that require more investigation in order to establish a sound theory of the relationship between music and development.

\section{References}

1. Madavo C (2005) Africa, the Development Challenges of the 21st Century Woodrow Wilson International Center for Scholars.

2. United Nations Children's Fund (2014) Generation 2030 Africa New York: UNICEF

3. UNECA U.N.E.C.f.A. (2014) Mdg Report 2014: Accessing Progressing Africa toward Millennium Development Goals Addis Ababa: Economic Commission for Africa.

4. Turino $T$ (2008) Music as social life: The politics of participation: University of Chicago Press.

5. Cook N (1994) A guide to musical analysis: Oxford University Press USA.

6. Cross I, Morley I (2009) The evolution of music: Theories, definitions and the nature of the evidence. Communicative musicality: Exploring the basis of human companionship, pp: 61-81.

7. Bastien S (2009) Reflecting and shaping the discourse: The role of music in AIDS communication in Tanzania. Social Science \& Medicine 68(7): 13571360.

8. Perris A (1985) Music as propaganda: art to persuade and to control: Greenwood Press.

9. Askew KM (2015) 'Eat squid not fish': poetics aesthetics and HIVIAIDS in Tanzania. Journal of African Cultural Studies 27(3): 255-276.

10. Olwage G (2008) Composing apartheid: Music for and against apartheid: Witwatersrand University Press.

11. Veal ME (2000) Fela: the life \& times of an African musical icon: Temple University Press

12. Agu DCC (2006) The Nigerian policy on education: Its impact on music education programme and delivery in Nigeria. Awka Journal of Research in Music and the Arts 3: 1-18.

13. Bingley K (2011) Bambeh's song: Music women and health in a rural community in post-conflict Sierra Leone.
14. Sen A (2000-2001) What's the Use of Music? The Role of the Music Industry in Africa.

15. Japhet G (2013) Edutainment: Using Stories and Media for Social Action and Behaviour Change: Johannesburg: Soul City Institute for Health and Development Communication.

16. Melouokouong O, Elessa M, Amvama and Naoussitatche (2012) Case Study of Music as a Tool of Advocacy and Awareness Raising. Yaounde: Living Earth Foundation \& Fondation Camerounaise de la Terre Vivante.

17. Wroughton L (2008) Poverty campaign inspires new U2 song says Bono.

18. BBC News (2004) Africa stars join for poverty song.

19. United Nations (2010) 8 Goals for Africa, "in We can end poverty: Millenium Development Goals and Beyond 2015 United Nations.

20. Soetan RO (2001) Culture gender and development. African Institute for Economic Development and Planning, Dakar, Senegal.

21. Ajisafe AK (1948) History of Abeokuta: Kash \& Klare Book Shop.

22. Diallo B (2014) West Africans get creative with Ebola awareness from Associated Press.

23. Jones S (2014) African musicians band together to raise Ebola awareness from Guardian.

24. Taylor A (2014) Listen: The Ebola song that isn't 'Do They Know It's Christmas? from The Washington Post.

25. Adewunmi B (2014) Band Aid 30: clumsy, patronising and wrong in so many ways.

26. Tucker B (2014) Beats rhymes and Ebola. Cultural Anthropology Online, 7th October.

27. Olori T (1997) MUSIC-NIGERIA: There's A Message in the Sound.

28. Kamuh A (2014) Gospel music inspires people to action in Democratic Republic of Congo. from World Vision International.

29. Barz G, Cohen J (2011) The Culture of AIDS in Africa: Hope and healing through music and the arts: Oxford University Press.

30. Amu M (2001) Music and health messages. Institute of African Studies Research Review 17(1): 91-95.

31. Easterly W (2006) The White Man's Burden: Why the West's Efforts to Aid the Rest Have Done So: New York: Penguin Press.

32. Radiaid (2016) Radi-Aid: Africa for Norway. 